\title{
Comparison of SMR, PMR, and PCMR in a cohort of union members potentially exposed to diesel exhaust emissions
}

\author{
O WONG, R W MORGAN, L KHEIFETS, AND S R LARSON
}

From the Environmental Health Associates, Inc, Oakland, CA 94607, USA

ABSTRACT A comparison of cause specific standarised mortality ratios (SMRs) and proportionate mortality ratios (PMRs) or proportionate cancer mortality ratios (PCMRs) was made based on the mortality experience of a cohort of 34156 members of a heavy equipment operators union. Two types of PMRs or PCMRs were used in the comparison: those based on all deaths and those based on deaths known to the union only. The comparison indicated that, for the entire cohort, both types of PMRs were poor indicators for cancer risk and produced a large number of false positives. On the other hand, PCMRs appeared to be better than PMRs for assessing the direction of site specific cancer risk, but they tended to overstate the magnitude of risk. Analysis by duration of union membership or latency indicated that PMRs or PCMRs based on deaths known to the union tended to overestimate the risk of lung cancer by disproportionately larger amounts in groups with shorter time than in groups with longer time. This differential bias had the net effect of reducing the gradient of any trend or eliminating the trend entirely. In conclusion, PMR or PCMR, based on reasonably sufficient death ascertainment, has a certain usefulness in generating hypotheses, but they are not useful or reliable in measuring the magnitude of risk or in detecting trends in dose response analysis. No conclusion should be drawn from either PMR or PCMR.

Two measures of mortality commonly used in occupational epidemiological studies are the proportionate mortality ratio (PMR) and the standardised mortality ratio (SMR). The PMR examines the pattern of mortality by proportion due to a specific cause. It gives no information as to whether overall or cause specific mortality rates are high or low. As such, the PMR does not necessarily measure risk. The SMR compares mortality rates from each cause with a standard population. Because it deals with the actual rates, the SMR measures risk and is usually more informative. It requires, however, considerable knowledge (number, age) of the population under study. The PMR requires no data other than the age, sex, and cause of death of the known dead.

PMR studies have flourished during the past few years. ${ }^{1-7}$ There are three likely explanations for this phenomenon. Firstly, PMR studies are easy and quick, and have some utility for hypothesis generation. Secondly, unions often collect death certificates

Received 13 August 1984 Accepted 1 October 1984 for their members and these death certificates are readily available. Thirdly, epidemiologists who have no access to population (denominator) data find union death certificates an attractive alternative data source. Fourthly, unions have been increasingly cooperative.

There is considerable concern about the relation of the PMR to the SMR. Some of the methodological problems of PMRs are well known among epidemiologists, and have been the subject of several publications, ${ }^{8-16}$ including a recent article in the British Journal of Industrial Medicine. ${ }^{17}$ The two major problems usually identified are:

(1) The "seesaw" effect-if one or more causes of death are low (which is usually the case for heart diseases in industrial groups due to the "healthy worker effect') other causes such as cancer will be automatically high, even when there is no true risk; and

(2) incomplete death ascertainment-since, in most PMR studies only a certain portion of deaths is available for analysis, there is a strong likelihood of bias. 
Table 1 Distribution by vital status (as of 31 December 1978) of the total cohort of local 3-3A members

\begin{tabular}{lcc}
\hline Vital status & Frequency & Percentage \\
\hline Living & 29046 & $85.0 \%$ \\
Deceased & 3305 & $9.7 \%$ \\
With death certificates & $(3243)$ & $(98.1 \%)$ \\
Without death certificates & $(62)$ & $(1.9 \%)$ \\
Unknown & 1805 & $5.3 \%$ \\
Total & 34156 & $100.0 \%$ \\
\hline
\end{tabular}

For instance, a recent National Cancer Institute-Oil, Chemical and Atomic Workers International Union (NCI-OCAW) study' used only active union members' deaths, so that there were practically no deaths from heart disease or chronic obstructive lung disease. Inevitably, that deficit, through the seesaw effect, will create a relatively high PMR for other diseases, including some rapidly lethal cancers. It is difficult to refute or confirm the associations inferred without proceeding to much more extensive research.

More recently, in an attempt to overcome partially the seesaw effect proportionate cancer mortality ratio (PCMR) based on cancer deaths has been proposed. The rationale for using PCMR is that the healthy worker effect has minimal impact on cancers.

Given that union based PMR or PCMR studies will continue, it is important to evaluate the validity of using these PMRs or PCMRs for risk assessment. A 1983 article in the British Journal of Industrial Medicine examined empirically the bias associated with SMRs and PMRs based only on employers' records. ${ }^{17}$ In that study, however, some of the groups examined were relatively small. In the present report we have compared cause specific SMRs and PMRs/PCMRs in a cohort of some 34000 members of a heavy equipment operators union. The objective of the study was to determine the concordance (or lack of it) between cause specific SMRs and several types of PMRs or PCMRs based on complete death ascertainment, as well as on deaths known to the union only. Based on these results, the validity of using PMRs or PCMRs based only on deaths known to the union in risk assessment was evaluated.

\section{Materials and method}

\section{DESCRIPTION OF DATA BASE}

An unusual opportunity existed to compare, on a single population, the PMRs or PCMRs based on union identified deaths, PMRs, or PCMRs for the total cohort, and the relevant SMRs. The cohort consisted of 34156 male heavy equipment operators with potential exposure to diesel exhaust emissions, who were members of the International Union of Operating Engineers, Locals 3 and $3 \mathrm{~A}$, for at least a year between 1 January 1964 and 31 December 1978. The results of this historical prospective mortality study, based on an SMR analysis, have been reported elsewhere. ${ }^{18}$

The vital status as of 31 December 1978 was determined for $32351(94.7 \%)$ of these union members. Among them, $29046(85.0 \%)$ were still living and $3305(9 \cdot 7 \%)$ had died. Death certificates were obtained for 3243 deaths $(98.1 \%$ of all deaths). Table 1 shows the distribution by vital status of the total cohort. It should be pointed out that in the SMR report 102 union members were listed as dead without death certificates. ${ }^{18}$ These individuals were treated as deaths with unknown cause in that report-that is, they were included in the overall SMR but not in any cause specific SMRs. Since PMRs are more sensitive to the number of deaths with unknown cause than SMRs, these 102 presumed deaths were reviewed. It was determined that death information on $\mathbf{4 0}$ of them was not completely convincing and it would be more appropriate to classify these 40 cases as "vital status unknown" rather than "deceased."

Table 2 shows the distribution of all deaths in the entire cohort. The union identified a total of 2448 deaths. Among these, the union supplied death certificates on 2252 decedents. For the remaining 196 , the date of death (sometimes only an approximate date) and, in some cases, the place of death were available from union records. It was necessary to write to various state vital statistics departments for copies of death certificates. Of the 196 presumed deaths, 193 death certificates were obtained. A few additional deaths were identified by CW Sweeney

Table 2 Distribution of all deaths in the entire cohort of local 3-3A members by information source

\begin{tabular}{|c|c|c|c|}
\hline \multirow[t]{2}{*}{ Source of vital status information } & \multirow[t]{2}{*}{ Total No of deaths } & \multicolumn{2}{|c|}{ Death certificates } \\
\hline & & Obtained & Not obtained \\
\hline $\begin{array}{l}\text { Death certificate from union } \\
\text { Union information } \\
\text { Fund information } \\
\text { SSA follow up } \\
\text { Total }\end{array}$ & $\begin{array}{rr}2252 & (68 \cdot 1 \%) \\
196 & (5 \cdot 9 \%) \\
253 & (7 \cdot 7 \%) \\
604 & (18 \cdot 3 \%) \\
3305 & (100 \cdot 0 \%)\end{array}$ & $\begin{array}{r}2252 \\
193 \\
226 \\
562 \\
3243\end{array}$ & $\begin{array}{r}0 \\
3 \\
17 \\
42 \\
62\end{array}$ \\
\hline
\end{tabular}

SSA = Social Security Administration. 
Table 3 Distribution of all deaths by union membership statis at time of death and by information source

\begin{tabular}{|c|c|c|c|c|c|}
\hline \multirow[t]{2}{*}{ Membership status } & \multicolumn{3}{|c|}{ Union deaths } & \multicolumn{2}{|c|}{ Total deaths } \\
\hline & No & Column (\%) & $\%$ of total deaths & No & Column (\%) \\
\hline $\begin{array}{l}\text { Separated } \\
\text { Retired } \\
\text { Active } \\
\text { Total }\end{array}$ & $\begin{array}{r}241 \\
1153 \\
1054 \\
2448\end{array}$ & $\begin{array}{r}9 \cdot 8 \\
47 \cdot 1 \\
43 \cdot 1 \\
100 \cdot 0\end{array}$ & $\begin{array}{l}31 \cdot 5 \\
88 \cdot 3 \\
85 \cdot 3 \\
74 \cdot 1\end{array}$ & $\begin{array}{r}764 \\
1306 \\
1235 \\
3305\end{array}$ & $\begin{array}{r}23 \cdot 1 \\
39 \cdot 5 \\
37 \cdot 4 \\
100 \cdot 0\end{array}$ \\
\hline
\end{tabular}

\& $\mathrm{Co}$, an independent administrator for numerous trust funds, including locals 3-3A. A total of 253 deaths were identified through this source (the "fund"), and, of these, 226 death certificates were obtained from state vital statistics departments subsequently. Names and social security numbers of the remaining union members with unknown vital status were sent to the Social Security Administration (SSA) for additional follow up. SSA identified 604 deaths, for which 562 death certificates were subsequently obtained. It should be pointed out that this particular union maintained excellent vital status information on its members (when compared with other unions): $74 \%$ of the total number of deaths (among active, retired, and separated members) were identified through union records.

As mentioned earlier, the purpose of this project was to evaluate, based on the conventional SMRs, the validity of PMRs or PCMRs for risk assessment. Furthermore, evaluation of PMRs or PCMRs based on deaths known to the union was of particular interest, since these deaths were readily available for this type of analysis. As such, we label the 2448 deaths identified through the union records as "union deaths" and all deaths identified by the union, the fund, and SSA as "total deaths." We will compare PMRs and PCMRs based on these two sets of deaths with the conventionalal SMRs based on all deaths in the entire cohort.

Table 3 shows the distributions of deaths by union membership status at time of death among the union deaths and the total deaths. As expected, the union deaths were primarily among retired and active members. The union identified $88.3 \%$ of deaths in the retirees and $85.3 \%$ in the active members. Because it provides death benefits and because members promoted to supervisory positions retain membership and benefits, the union probably has a more complete knowledge of deaths among retirees than many other unions. On the other hand, but as expected, only $31.5 \%$ of deaths amonst the separated members were known to the union.

Table 4 shows the distribution of deaths by duration of union membership and information source. The union deaths appear to have a slightly longer duration of membership - that is, deaths of long term union members were more likely to be known to the union. The percentage of union death ascertainment increased with increasing duration of membership.

\section{METHODOLOGICAL ISSUES}

The measure commonly used in a prospective mortality study is the SMR. The SMR, a particular measure of relative risk, is the ratio of the mortality rate of an exposed cohort to the mortality rate of an unexposed control group, adjusted (by the indirect method) for age, race, and other confounding variables. It can be shown that SMR is also the ratio of observed deaths to expected deaths based on the indirect adjustment.

In many cases the population at risk cannot be defined because of either inadequate records or limited resources. The number of deaths in a certain group is known, however, and death certificates are available. Although a rate (hence SMR) cannot be

Table 4 Distribution of deaths by duration of union membership and by information source

\begin{tabular}{|c|c|c|c|c|c|}
\hline \multirow{2}{*}{$\begin{array}{l}\text { Duration of membership } \\
\text { (years) }\end{array}$} & \multicolumn{3}{|c|}{ Union deaths } & \multicolumn{2}{|c|}{ Total deaths } \\
\hline & No & Column (\%) & $\%$ of total deaths & No & Column (\%) \\
\hline $\begin{array}{c}<2 \\
2-4 \\
5-9 \\
10-14 \\
15-19 \\
20-24 \\
25-29 \\
30-34 \\
35-39 \\
\geqslant 40 \\
\text { Total }\end{array}$ & $\begin{array}{r}6 \\
84 \\
205 \\
368 \\
443 \\
472 \\
525 \\
281 \\
58 \\
6 \\
2448\end{array}$ & $\begin{array}{r}0.2 \\
3.4 \\
8.4 \\
15.0 \\
18.1 \\
19.3 \\
21.4 \\
11.5 \\
2.4 \\
0.2 \\
100.0\end{array}$ & $\begin{array}{l}20 \cdot 0 \\
40 \cdot 2 \\
54 \cdot 0 \\
69 \cdot 0 \\
75 \cdot 2 \\
81 \cdot 4 \\
85 \cdot 8 \\
91 \cdot 5 \\
98 \cdot 3 \\
85 \cdot 7 \\
74 \cdot 1\end{array}$ & $\begin{array}{r}30 \\
209 \\
379 \\
533 \\
589 \\
580 \\
612 \\
307 \\
59 \\
7 \\
3305\end{array}$ & $\begin{array}{r}0.9 \\
6.3 \\
11.5 \\
16.1 \\
17.8 \\
17.6 \\
18.5 \\
9.3 \\
1.8 \\
0.2 \\
100.0\end{array}$ \\
\hline
\end{tabular}


computed, the cause specific mortality experience may be evaluated using an index known as the PMR. The PMR is the ratio of the proportion of deaths from a specific cause in an exposed group to the corresponding proportion in an unexposed, adjusted for age, race, and other confounding variables. A PMR greater than 1 (or 100\%) indicates that there is a higher proportion of deaths due to a specific cause in the study group than in the controls. This may or may not mean a corresponding higher risk from the same cause.

The foundation of a proportionate mortality analysis is the ratio of deaths from a specific cause of interest to deaths from some large collection of causes, the latter quantity termed the "base." The usual practice is to use all deaths as the base. In occupational studies, however, the study group is usually suspected, a priori, to have a lower overall death rate than the general population (the "healthy worker effect") and thus the usual PMRs using gen- eral population as the comparison group might be expected to overstate the true risks.

One way to alleviate this problem is to choose as the base a set of causes for which the study and comparison groups might be more likely to have similar rates. This seems to be the case for cancer of all sites combined for industrial population $v$ the general population, and the term proportionate cancer mortality ratio (PCMR) is given to this type of analysis. Because cancer is relatively immune to the healthy worker effect whereas other causes-for example, cardiovascular diseases-are not, the ordinary PMR usually overestimates cancer risk. PCMRs are expected to be less inaccurate.

Perhaps one of the most important features of a PMR/PCMR study is the quality (in terms of the completeness of the set of deaths being studied) of data on which it is based. In occupational studies the total set of deaths that occur among all people who were ever employed in the industry being studied

Table 5 Cause specific SMRs, total PMRs, union PMRs, total PCMRs, and union PCMRs for the entire cohort of 34156 male local 3-3A members

\begin{tabular}{|c|c|c|c|c|c|}
\hline Cause of death (7th ICDA) & $S M R$ & $\begin{array}{l}\text { Total } \\
\text { PMR }\end{array}$ & $\begin{array}{l}\text { Union } \\
\text { PMR }\end{array}$ & $\begin{array}{l}\text { Total } \\
\text { PCMR }\end{array}$ & $\begin{array}{l}\text { Union } \\
P C M R\end{array}$ \\
\hline 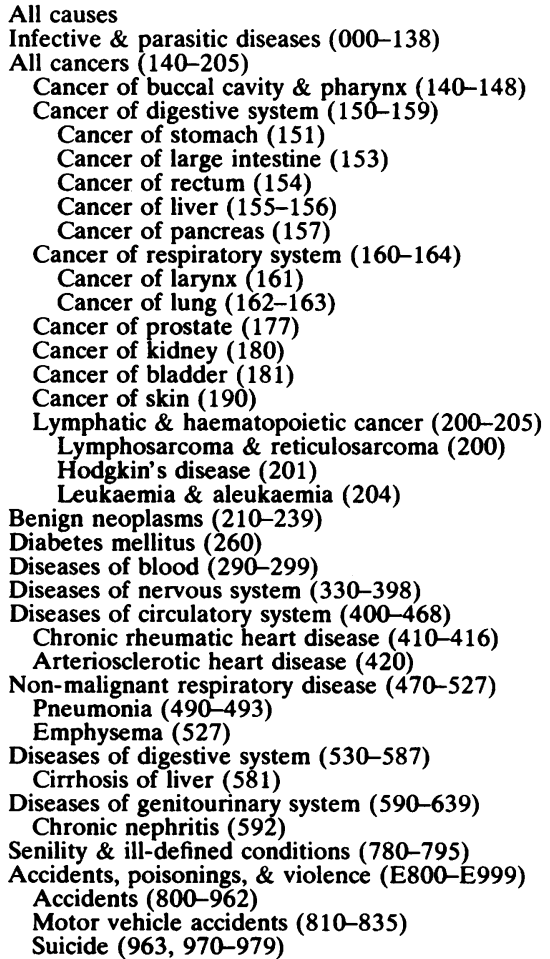 & $\begin{array}{c}80 \cdot 4 \dagger \\
66 \cdot 6 \\
93 \cdot 0^{*} \\
77 \cdot 0 \\
93 \cdot 3 \\
117 \cdot 6 \\
88 \cdot 4 \\
48 \cdot 4 \dagger \\
166 \cdot 7^{*} \\
96 \cdot 6 \\
96 \cdot 9 \\
71 \cdot 6 \\
98 \cdot 6 \\
87 \cdot 1 \\
73 \cdot 9 \\
118 \cdot 1 \\
96 \cdot 7 \\
84 \cdot 5 \\
98 \cdot 8 \\
87 \cdot 5 \\
77 \cdot 5 \\
151 \cdot 0 \\
61 \cdot 5 \dagger \\
74 \cdot 5 \\
63 \cdot 6 \dagger \\
71 \cdot 9 \dagger \\
58 \cdot 5^{*} \\
67 \cdot 8 \dagger \\
84 \cdot 4^{*} \\
54 \cdot 0 \dagger \\
165 \cdot 3 \dagger \\
72 \cdot 3 \dagger \\
80 \cdot 1^{*} \\
19 \cdot 8 \dagger \\
21 \cdot 5 \dagger \\
26 \cdot 1 \dagger \\
111 \cdot 4^{*} \\
127 \cdot 0 \dagger \\
107 \cdot 7 \\
97 \cdot 5\end{array}$ & $\begin{array}{c}100 \cdot 0 \\
85 \cdot 8 \\
115 \cdot 0 \dagger \\
96 \cdot 5 \\
116 \cdot 7^{*} \\
148 \cdot 9 \dagger \\
109 \cdot 1 \\
61 \cdot 3 \\
215 \cdot 8 \dagger \\
120 \cdot 8 \\
119 \cdot 3 \dagger \\
89 \cdot 6 \\
121 \cdot 2 \dagger \\
105 \cdot 8 \\
91 \cdot 5 \\
146 \cdot 6 * \\
117 \cdot 5 \\
104 \cdot 3 \\
126 \cdot 6 \\
109 \cdot 8 \\
95 \cdot 6 \\
189 \cdot 1 \dagger \\
76 \cdot 4 \\
93 \cdot 8 \\
79 \cdot 0 \dagger \\
90 \cdot 5 \dagger \\
74 \cdot 7 \\
85 \cdot 1 \dagger \\
104 \cdot 3 \\
67 \cdot 1 \dagger \\
210 \cdot 2 \dagger \\
90 \cdot 3 \\
99 \cdot 3 \\
25 \cdot 2 \\
28 \cdot 8 * \\
31 \cdot 8 \dagger \\
133 \cdot 2 \dagger \\
153 \cdot 9 \dagger \\
130 \cdot 2 \dagger \\
117 \cdot 0\end{array}$ & $\begin{array}{c}100 \cdot 0 \\
83 \cdot 4 \\
117 \cdot 1 \dagger \\
107 \cdot 1 \\
114 \cdot 4 \\
131 \cdot 8 \\
109 \cdot 4 \\
54 \cdot 8 \\
229 \cdot 6 \dagger \\
119 \cdot 9 \\
116 \cdot 3^{*} \\
95 \cdot 6 \\
117 \cdot 6^{*} \\
109 \cdot 3 \\
108 \cdot 6 \\
155 \cdot 8^{*} \\
112 \cdot 1 \\
114 \cdot 3 \\
157 \cdot 8 \\
106 \cdot 1 \\
98 \cdot 6 \\
196 \cdot 1^{*} \\
65 \cdot 5^{*} \\
106 \cdot 5 \\
87 \cdot 4 \\
92 \cdot 2 \dagger \\
78 \cdot 8 \\
86 \cdot 4 \dagger \\
105 \cdot 7 \\
72 \cdot 1 \\
208 \cdot 0 \dagger \\
88 \cdot 9 \\
92 \cdot 9 \\
21 \cdot 4 \dagger \\
13 \cdot 8^{*} \\
30 \cdot 8 \dagger \\
138 \cdot 9 \dagger \\
164 \cdot 0 \dagger \\
144 \cdot 5 \dagger \\
115 \cdot 4\end{array}$ & $\begin{array}{r}100 \cdot 0 \\
84 \cdot 4 \\
101 \cdot 0 \\
128 \cdot 8 \\
94 \cdot 2 \\
53 \cdot 0^{*} \\
187 \cdot 0 \dagger \\
104 \cdot 8 \\
103 \cdot 9 \\
78 \cdot 0 \\
105 \cdot 6 \\
88 \cdot 2 \\
80.1 \\
124 \cdot 7 \\
105 \cdot 1 \\
91 \cdot 3 \\
111 \cdot 1 \\
98 \cdot 2 \\
83 \cdot 3\end{array}$ & $\begin{array}{r}100.0 \\
91.3 \\
97.7 \\
112.7 \\
93.5 \\
46.8^{*} \\
196.4 \dagger \\
102.5 \\
99.5 \\
81.6 \\
100.7 \\
93.2 \\
92.9 \\
133.1 \\
96.2 \\
97.2 \\
133.6 \\
89.0 \\
83.9\end{array}$ \\
\hline
\end{tabular}

*Statistically significant at 0.05 level.

tStatistically significant at $\mathbf{0 . 0 1}$ level. 
may be subdivided into active, retired, and terminated employees. In most PMR/PCMR studies only one or two of these groups are included, since availability of the total group is tantamount to having access to a cohort suitable for an SMR study. This partial death ascertainment, an unlikely representative sample, may introduce bias in the results.

\section{Results}

Race was not always available from union membership records. According to the union, however, historically there were few non-white members. In our analysis the entire cohort will be assumed to consist of white men.

Cause of death was coded by EHA's nosologist according to the 7 th revision of the International Classification of Diseases. ${ }^{14}$ Deaths without death certificates were included with the category "cause unknown."

In this section SMRs, PMRs, and PCMRs on union deaths and total deaths will be presented for the entire cohort as well as for several selected subcohorts. The actual computations were performed by a standard computer program. ${ }^{20}$ The following terminology will be used to facilitate discussion:

SMR = SMR based on deaths from all follow up sources,

Total PMR = PMR based on deaths from all follow up sources,

Union PMR = PMR based on deaths identified through union records,

Total PCMR = PCMR based on deaths from all follow up sources, and

Union PCMR = PCMR based on deaths identified through union records.

\section{ANALYSIS FOR THE ENTIRE COHORT}

Tabe 5 shows the cause specific SMRs, total PMRs, Union PMRs, total PCMRs, and union PCMRs for the entire cohort. The overall SMR was 80.4 ( $p<$ 0.01 ), typical of an industrial cohort (the so-called healthy worker effect). The all cancer SMR of 93.0 was significantly less than expected $(p<0.05)$. Both total PMR and union PMR for cancer of all sites, however, were significantly raised, 115.0 and $117 \cdot 1$, respectively ( $p<0.01)$. Thus all cancer PMR, based on either set of deaths, gave misleading results. Based on total PMRs, one would be led to conclude, incorrectly, that there were significant excesses of mortality from cancer of the digestive system, stomach, respiratory system, lung, and bladder. In addition, several non-significant excesses were also incorrectly suggested by total PMRs-for example, cancer of large intestine, pancreas, prostate, skin, lymphatic and haematopoietic tissues, lymphosarcoma and reticulosarcoma, and Hodgkin's disease. Similar misleading results were suggested by union PMRs. Both total PMRs and union PMRs for site specific cancers were grossly inflated.

For non-malignant causes of death, there appears to be a fair agreement between SMRs and total PMRs or union PMRs. One of the important disagreements was benign neoplasms. The SMR was raised $(151.0)$ but not significant, whereas the total PMR was 189.1 ( $p<0.01)$ and union PMR 196.1 $(p<0.05)$. Another disagreement was nonmalignant respiratory disease; the SMR indicated a significant deficit, whereas both total PMR and union PMR suggested a small non-significant excess. Nevertheless, both total PMRs and union PMRs identified, correctly, many significant excesses, as well as deficits.

For cancer risk assessment, on the other hand, PCMRs based on either total deaths or union deaths showed a high degree of agreement with SMR, although the magnitude of individual PCMR was somewhat higher than the corresponding SMR. Both total PCMR and union PCMR correctly identified a significant deficit in cancer of the rectum and a significant excess in cancer of the liver. One exception was that union PCMR indicated, incorrectly, a $33 \%$ increase in lymphosarcoma and reticulosarcoma when the SMR showed no excess.

ANALYSIS BY DURATION OF UNION MEMBERSHIP In the original study duration of union membership was used as a surrogate measure of duration of potential exposure to diesel exhaust emissions. Cause specific SMRs by duration of union membership for the entire cohort have been reported elsewhere. ${ }^{18}$ Based on SMRs, no obvious trend was detected for any site specific cancer, except for cancer of the lung. Table 6 summarises the comparison of trends in lung cancer mortality by duration of union membership based on SMR, total PMR, union PMR, total PCMR, and union PCMR. For cancer of the lung, SMR started at 45.3 for under five years of membership, increased to 73.8 for five to nine years, reached 107.5 for $10-14$ years, and remained at that level thereafter. A similar trend was observed for lung cancer based on total PMRs; however, the magnitude of the PMR at each interval was slightly higher than the corresponding SMR. On the other hand, there was no apparent trend for lung cancer according to union PMRs or union PCMRs. The disappearance of the trend was due to differential overestimation of risk by duration of union membership. Thus PMRs and PCMRs were confounded by duration of union membership. Perhaps this was, in turn, the result of an increased death 
Table 6 Comparison of trends in lung cancer mortality by duration of union membership based on SMR, total PMR, union PMR, total PCMR, and union PCMR

\begin{tabular}{|c|c|c|c|c|c|c|c|}
\hline \multirow[t]{2}{*}{ Index } & \multicolumn{5}{|c|}{ Duration of union membership } & \multirow[t]{2}{*}{ Slope } & \multirow[t]{2}{*}{ Intercept } \\
\hline & $<5$ & $5-9$ & $10-14$ & $15-19$ & $\geqslant 20$ & & \\
\hline $\begin{array}{l}\text { SMR } \\
\text { Total PMR } \\
\text { Union PMR } \\
\text { Total PCMR } \\
\text { Union PCMR }\end{array}$ & $\begin{array}{l}45 \cdot 3 \\
61 \cdot 1 \\
94 \cdot 2 \\
75 \cdot 2 \\
97 \cdot 3\end{array}$ & $\begin{array}{r}74 \cdot 9 \\
95 \cdot 8 \\
107 \cdot 8 \\
76 \cdot 8 \\
84 \cdot 7\end{array}$ & $\begin{array}{r}107 \cdot 5 \\
131 \cdot 8 \\
95 \cdot 8 \\
110 \cdot 4 \\
84 \cdot 0\end{array}$ & $\begin{array}{r}102 \cdot 2 \\
121 \cdot 8 \\
119 \cdot 8 \\
103 \cdot 9 \\
99 \cdot 4\end{array}$ & $\begin{array}{l}107 \cdot 3 \\
130 \cdot 8 \\
125 \cdot 1 \\
114 \cdot 1 \\
107 \cdot 8\end{array}$ & $\begin{array}{l}3 \cdot 03 \\
3 \cdot 31 \\
1 \cdot 48 \\
2 \cdot 10 \\
0 \cdot 71\end{array}$ & $\begin{array}{l}49 \cdot 62 \\
66 \cdot 91 \\
90 \cdot 05 \\
69 \cdot 86 \\
85 \cdot 72\end{array}$ \\
\hline
\end{tabular}

ascertainment through union records with increasing duration of membership (table 4). In the under five years group the union PMR or PCMR for lung cancer overestimated the mortality experienced by more than $100 \%(94.2$ and $97.3 \vee 45.3)$, but the corresponding overestimate in the 20 or more years' group was proportionally much less $(125 \cdot 1$ or $107 \cdot 8$ $v$ 107.3).

As a means to compare the trends, these data were fitted to a linear regression model, and the slopes and the intercepts are presented in table 6 . The slopes clearly indicated that the union PMRs or PCMRs greatly underestimated the gradients of the trends. Thus, based on either union PMRs or PCMRs, the trend in lung cancer by duration of union membership would have been missed.

It has been suggested that PMRs based on union deaths among long term members are less, biased. ${ }^{13}$ In the present study we found that the overestimate of risk by PMR was somewhat inversely proportional to the duration of union membership. Table 7, however, shows that PMRs (particularly those based on union deaths only) with a fairly long membership-for instance, 20 or more years-were still unsatisfactory as a substitute or surrogate for SMR because of the false positives (digestive cancer, lung cancer, accidents).

\section{ANALYSIS BY LATENCY}

Cause specific SMRs by latency $(<10,10-19, \geqslant 20$ years) for the entire cohort have been presented elsewhere. ${ }^{18}$ For all causes, although the SMRs in all three latent periods were significantly less than 100 , there was an upward trend with increasing latency $(\mathrm{SMR}=71.4,79.5,84 \cdot 1)$. This observation probably reflected the diminishing healthy worker effect. $^{21}{ }^{22}$ Upward trends were also evident for all

Table 7 Cause specific SMRs, total PMRs, union PMRs, total PCMRs, and union PCMRs for cohort members with at least 20 years of union membership

\begin{tabular}{|c|c|c|c|c|c|}
\hline Cause of death (7th ICDA) & $S M R$ & Total PMR & Union PMR & Total PCMR & Union PCMR \\
\hline $\begin{array}{l}\text { All causes } \\
\text { All cancers (140-205) } \\
\text { Cancer of digestive system (150-159) } \\
\text { Cancer of stomach (151) } \\
\text { Cancer of large intestine (153) } \\
\text { Cancer of liver (155-156) } \\
\text { Cancer of respiratory system (160-164) } \\
\text { Cancer of lung (162-163) } \\
\text { Cancer of prostate }(177) \\
\text { Cancer of kidney (180) } \\
\text { Cancer of bladder (181) } \\
\text { Cancer of skin (190) } \\
\text { Lymphatic \& haematopoietic cancer (200-205) } \\
\text { Lymphosarcoma \& reticulosarcoma (200) } \\
\text { Leukaemia \& aleukaemia (204) } \\
\text { Diseases of nervous system (330-398) } \\
\text { Diseases of circulatory system (400-468) } \\
\text { Arteriosclerotic heart disease (420) } \\
\text { Non-malignant respiratory disease (470-527) } \\
\text { Emphysema (527) } \\
\text { Diseases of digestive system (530-587) } \\
\text { Cirrhosis of liver (581) } \\
\text { Diseases of genitourinary system (590-639) } \\
\text { Chronic nephritis (592) } \\
\text { Accidents, poisonings, \& violence (E800-E999) } \\
\text { Accidents (800-962) } \\
\text { Suicide (963, 970-979) }\end{array}$ & $\begin{array}{c}81 \cdot 1 \dagger \\
93.9 \\
82 \cdot 2 \\
87.9 \\
97 \cdot 5 \\
118 \cdot 0 \\
105 \cdot 0 \\
107 \cdot 3 \\
89 \cdot 9 \\
56 \cdot 3 \\
114 \cdot 7 \\
113 \cdot 7 \\
85 \cdot 2 \\
124 \cdot 4 \\
78 \cdot 8 \\
77 \cdot 9 \dagger \\
74 \cdot 4 \dagger \\
69 \cdot 9 \dagger \\
94 \cdot 2 \\
174 \cdot 8 \dagger \\
80 \cdot 8 \\
95 \cdot 2 \\
5 \cdot 3 \dagger \\
-99.1 \\
116 \cdot 2 \\
78.8\end{array}$ & $\begin{array}{c}100 \cdot 0 \\
115 \cdot 0 \dagger \\
101 \cdot 5 \\
109.7 \\
118.7 \\
150.3 \\
128.2 \dagger \\
130.8 \dagger \\
106.3 \\
69 \cdot 3 \\
139.3 \\
139.6 \\
104.6 \\
158 \cdot 7 \\
96.6 \\
94.8 \\
92.2 \dagger \\
86.5 \dagger \\
114.3 \\
217.3 \dagger \\
101.0 \\
118.8 \\
6.6 \dagger \\
\overline{123} \\
12.9 * \\
146.6 \dagger \\
98.4\end{array}$ & 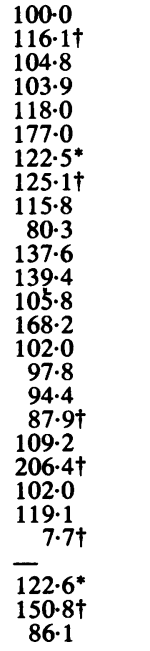 & $\begin{array}{r}100.0 \\
88.0 \\
95.3 \\
102.8 \\
130.2 \\
111.8 \\
114.1 \\
90.2 \\
60.8 \\
119.3 \\
125.3 \\
91.2 \\
139.2 \\
84.0\end{array}$ & $\begin{array}{r}100.0 \\
90.3 \\
89.8 \\
101.7 \\
152.3 \\
105.5 \\
107.8 \\
69.4 \\
69.4 \\
118.4 \\
121.1 \\
90.8 \\
144.2 \\
87.5\end{array}$ \\
\hline
\end{tabular}

*Statistically significant at 0.05 level.

†Statistically significant at 0.01 level. 
cancers, cancer of the lung, and cancer of the skin. ${ }^{18}$ In this report we will limit our detailed discussion to lung cancer only. Table 8 shows the SMR, total PMR, union PMR, total PCMR, and union PCMR for lung cancer by latency. The table also provides the slopes of SMRs and various PMRs and PCMRs based on a linear regression model. The three SMRs for lung cancer in order of increasing latency were $65 \cdot 6,89 \cdot 5$, and $112 \cdot 2$. Total PMRs for lung cancer gave a comparable gradient to that of SMR, but consistently overestimated the magnitude of risk for each latency. Union PMRs did not suggest a straightly upward trend by latency for lung cancer. Both total PCMRs and union PCMRs correctly indicated an upward trend by latency for lung cancer, but the slope of the trends was much reduced. This observation reflected the disproportional overestimate of lung cancer risk by PCMRs for short latency as compared with long latency. Clearly, the union PMR, and to a lesser extent the union PCMR, overestimated the SMR when latency was under 10 years. As latency increased, the union PMR and PCMR approximate the SMR more closely. Clearly, both union PMR and PCMR completely underestimated the gradient of the trend in latency.

Similarly, total PMRs suggested a less steep slope for the gradient of all cancers $(110 \cdot 0,113 \cdot 9,116 \cdot 8)$, as compared with the one indicated by SMRs (76.6, $90 \cdot 8,98 \cdot 8)$. Union PMRs failed completely in detecting any gradient for all cancers $(123 \cdot 3,112.9$, 117.9). Neither total PCMRs nor union PCMRs, by definition, provide any information on the trend of all cancers.

For non-malignant causes of death, both the total PMRs and the union PMRs failed to detect the trend in arteriosclerotic heart disease (total PMR $=81.7$, $282 \cdot 2,84 \cdot 8$; union PMR $=73 \cdot 7,90 \cdot 0,86 \cdot 6$ ), when compared with the trends provided by SMRs $(54 \cdot 7$, $68 \cdot 1,71 \cdot 1)$. For malignant respiratory disease, however, analysis of total PMRs by latency $(45 \cdot 7,96 \cdot 3$, $118.3)$ did detect the trend that was found with the SMR analysis $(30 \cdot 4,76 \cdot 3,100 \cdot 3)$. Similarly, union PMRs also detected the trend in non-malignant

Table 8 Comparison of trends in lung cancer mortality by latency based on SMR, total PMR, union PMR, total $P C M R$, and union PCMR

\begin{tabular}{|c|c|c|c|c|c|}
\hline \multirow[t]{2}{*}{ Index } & \multicolumn{3}{|c|}{ Latency (years) } & \multirow[t]{2}{*}{ Slope } & \multirow[t]{2}{*}{ Intercept } \\
\hline & $<10$ & $10-19$ & $\geqslant 20$ & & \\
\hline $\begin{array}{l}\text { SMR } \\
\text { Total PMR } \\
\text { Union PMR } \\
\text { Total PCMR } \\
\text { Union PCMR }\end{array}$ & $\begin{array}{r}65 \cdot 6 \\
94 \cdot 5 \\
109 \cdot 0 \\
84 \cdot 4 \\
87 \cdot 1\end{array}$ & $\begin{array}{r}89.5 \\
111.6 \\
105.0 \\
98.7 \\
93.5\end{array}$ & $\begin{array}{l}112 \cdot 2 \\
132 \cdot 1 \\
124 \cdot 6 \\
113 \cdot 5 \\
105 \cdot 8\end{array}$ & $\begin{array}{l}2.33 \\
1.88 \\
0.78 \\
1.46 \\
0.94\end{array}$ & $\begin{array}{r}54 \cdot 15 \\
84 \cdot 53 \\
101 \cdot 17 \\
77 \cdot 04 \\
81 \cdot 44\end{array}$ \\
\hline
\end{tabular}

respiratory disease correctly but with a less steep slope $(61 \cdot 4,97 \cdot 8,114 \cdot 0)$.

Table 9 compares cause specific SMRs, total PMRs, union PMRs, total PCMRs, and union PCMRs for cohort members with at least 20 years of latency. The table clearly indicates the inadequacy of both total PMRs and union PMRs, which show a number of false positives (all cancers, cancer of the large intestine, lung cancer, accidents) among those cohort members with a long latency.

\section{ANALYSIS BY UNION DISPATCH (EXPOSURE) HISTORIES}

In the original study partial work histories were available from the annual dispatch tapes (1967-78) maintained by the union. These dispatch tapes contained about 200 different job titles. Assisted by union personnel, we reduced these job titles to 20 functional job titles, which were further grouped into three categories of potential exposure (high, low, and unknown) to diesel exhaust emissions. These exposure assignments were based on the description of the duties of the job and the proximity of the job to a diesel exhaust emission source as provided by the union. The 20 functional job titles by potential exposure category are as follows:

\section{High exposure}

Scraper operator

Loader operator

Dozer operator

Backhoe operator

\section{Low exposure \\ Blade operator \\ Roller operator \\ Mechanical maintenance Crane operator worker \\ Engineer (rodman, etc) Clam shell worker

Stationary equipment
operator
Crane operator
Boom lift operator
Clam shell worker

\section{Unknown exposure}

Oil field worker

Asphalt plant and paving worker

Concrete and paving worker
Specialty

Canal worker

Specific project worker

Miscellaneous

\section{Marine worker}

Table 10 provides the cause specific SMRs, total PMRs, total PCMRs, union PMRs, and union PCMRs for union members who were most frequently dispatched in the low exposure category. The SMR (82.9) for all cancers was significantly low, whereas the total PMR (122.5) and union PMR $(124 \cdot 2)$ for all cancers were both significantly high $(p<0.01$ ). In fact, both PMRs overestimated the risk by about $50 \%$. For cancer of the digestive system, SMR was $84 \cdot 0$, but all PMRs and PCMRs were above 100 , although the rise was not significant. 
Table 9 Cause specific SMRs, total PMRs, union PMRs, total PCMRs, and union PCMRs for cohort members with at least 20 years of latency

\begin{tabular}{|c|c|c|c|c|c|}
\hline Cause of death (7th ICDA) & $S M R$ & $\begin{array}{l}\text { Total } \\
\text { PMR }\end{array}$ & $\begin{array}{l}\text { Union } \\
P M R\end{array}$ & $\begin{array}{l}\text { Total } \\
\text { PCMR }\end{array}$ & $\begin{array}{l}\text { Union } \\
\text { PCMR }\end{array}$ \\
\hline $\begin{array}{l}\text { All causes } \\
\text { All cancers (140-205) } \\
\text { Cancer of digestive system (150-159) } \\
\text { Cancer of stomach (151) } \\
\text { Cancer of large intestine }(153) \\
\text { Cancer of liver (155-156) } \\
\text { Cancer of respiratory system (160-164) } \\
\text { Cancer of lung (162-163) } \\
\text { Cancer of prostate (177) } \\
\text { Cancer of kidney (180) } \\
\text { Cancer of bladder (181) } \\
\text { Cancer of skin (190) } \\
\text { Lymphatic \& haematopoietic cancer (200-205) } \\
\text { Lymphosarcoma \& reticulosarcoma (200) } \\
\text { Leukaemia \& aleukaemia (204) } \\
\text { Diseases of nervous system (330-398) } \\
\text { Diseases of circulatory system (400-468) } \\
\text { Arteriosclerotic heart disease (420) } \\
\text { Non-malignant respiratory disease (470-527) } \\
\text { Emphysema (527) } \\
\text { Diseases of digestive system (530-587) } \\
\text { Cirrhosis of liver (581) } \\
\text { Diseases of genitourinary system (590-639) } \\
\text { Chronic nephritis (592) } \\
\text { Accidents, poisonings, \& violence (E800-E999) } \\
\text { Accidents (800-962) } \\
\text { Suicide ( } 963,970-979)\end{array}$ & $\begin{array}{l}84 \cdot 1 \dagger \\
98 \cdot 8 \\
89 \cdot 9 \\
83 \cdot 2 \\
114 \cdot 7 \\
118 \cdot 5 \\
110 \cdot 5 \\
112 \cdot 2 \\
83 \cdot 6 \\
58 \cdot 9 \\
107 \cdot 2 \\
131 \cdot 7 \\
85 \cdot 7 \\
123 \cdot 9 \\
82 \cdot 6 \\
77 \cdot 3 \dagger \\
76 \cdot 3 \dagger \\
71 \cdot 1 \dagger \\
100 \cdot 3 \\
199 \cdot 4 \dagger \\
85 \cdot 4 \\
101 \cdot 5 \\
14 \cdot 1 \dagger \\
32 \cdot 0 \\
103 \cdot 2 \\
114 \cdot 1 \\
100 \cdot 4\end{array}$ & $\begin{array}{c}100 \cdot 0 \\
116 \cdot 8 \dagger \\
107 \cdot 2 \\
100 \cdot 2 \\
135 \cdot 3^{*} \\
145 \cdot 5 \\
130 \cdot 2 \dagger \\
132 \cdot 1 \dagger \\
97 \cdot 1 \\
69 \cdot 7 \\
126 \cdot 8 \\
154 \cdot 2 \\
101 \cdot 3 \\
151 \cdot 3 \\
97.6 \\
91 \cdot 3 \\
91 \cdot 1 \dagger \\
84 \cdot 8 \dagger \\
118 \cdot 3 \\
240.9 \dagger \\
101 \cdot 8 \\
120.2 \\
16 \cdot 9 \dagger \\
40.2 \\
121.5^{*} \\
135 \cdot 8 \dagger \\
118 \cdot 1\end{array}$ & 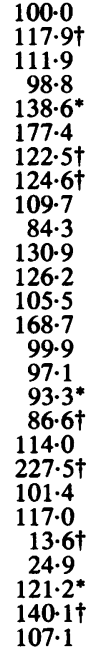 & $\begin{array}{r}100 \cdot 0 \\
91.3 \\
85.3 \\
114.9 \\
123.3 \\
111.9^{*} \\
113 \cdot 5^{*} \\
80.0 \\
60.3 \\
106.3 \\
136.5 \\
87.0 \\
130.7 \\
83.3\end{array}$ & $\begin{array}{r}100 \cdot 0 \\
94.7 \\
84.7 \\
117 \cdot 3 \\
149 \cdot 8 \\
104.0 \\
105.8 \\
92.3 \\
71.8 \\
110 \cdot 6 \\
108 \cdot 4 \\
89.0 \\
142.7 \\
84.4\end{array}$ \\
\hline
\end{tabular}

*Statistically significant at 0.05 level.

†Statistically significant at 0.01 level.

In the same group of union members both total PMR (151.1, p < 0.05) and union PMR (149.9, p $<0.05)$ gave significant false positives for cancer of large intestine $(\mathrm{SMR}=103 \cdot 5)$. Disagreement also existed between PMRs and SMR for cancer of the liver. Finally, for cancer of the lung, SMR was $86 \cdot 0$, but the corresponding total PMR was 124.7 ( $p<0.05)$. Again, PCMRs based on either set of deaths appeared to be somewhat closer to the corresponding SMRs than did PMRs, but they were still consistently higher than the SMRs. In many cases the overestimate was sufficient to turn a deficit into an excess (cancer of pancreas, cancer of kidney, lymphosarcoma and reticulosarcoma, and leukaemia, for example).

In the high exposure group (table 11) the nonsignificant SMR of 173.4 for liver cancer was turned into significant PMR (293.8) and PCMR (264.2) based on union deaths. For cancer of the respiratory system, the deficit in SMR was turned into an excess by PMRs and PCMRs, although the excess was not statistically significant. A similar pattern was found for lymphatic and haematopoietic cancer.

Also in the high exposure group significant false positives, as indicated by total PMR and union PMR, were found for motor vehicle accidents.

Table 12 presents the SMRs and PMRs and PCMRs for those union members who did not have any dispatch history between 1967 and 1978. The lack of dispatch history meant that the individual performed the same job for the entire period. This group was interesting to examine, because the overall SMR was exactly 100 , and the all cancer SMR was actually significantly high. Both total PMR and union PMR correctly identified the significant excess of cancer. PCMRs, by definition, did not address this issue. In fact, some PCMRs actually underestimate some site specific cancer risk. For example, SMR for stomach cancer was $199.1(p<0.01)$ but the union PCMR for stomach cancer was 160.5 , not 8 significant. Thus in this group union PCMR failed to identify the significant excess in stomach cancer. 음 Similarly, for lung cancer, the SMR indicated a significant $20 \%$ increase, but the union PCMR actually indicates a slight deficit.

ANALYSIS BY UNION MEMBERSHIP STATUS

In Table 13 PMRs of selected causes of death in active and retired workers from union records were compared with the SMRs for the entire cohort. Clearly, there were major discrepancies. For example, analysis of union records would indicate a significant excess of all cancers for both active and 7 retired groups, yet the total cohort analysis showed a $\bar{O}$ significant deficit of all cancers. For many individual cancer sites, the magnitude of the excess was much 
Table 10 Cause specific SMRs, total PMRs, union PMRs, total PCMRs, and union PCMRs for local 3-3A members who were most frequently dispatched in the low exposure category

\begin{tabular}{|c|c|c|c|c|c|}
\hline Cause of death (7th ICDA) & $S M R$ & $\begin{array}{l}\text { Total } \\
\text { PMR }\end{array}$ & $\begin{array}{l}\text { Union } \\
P M R\end{array}$ & $\begin{array}{l}\text { Total } \\
\text { PCMR }\end{array}$ & $\begin{array}{l}\text { Union } \\
\text { PCMR }\end{array}$ \\
\hline 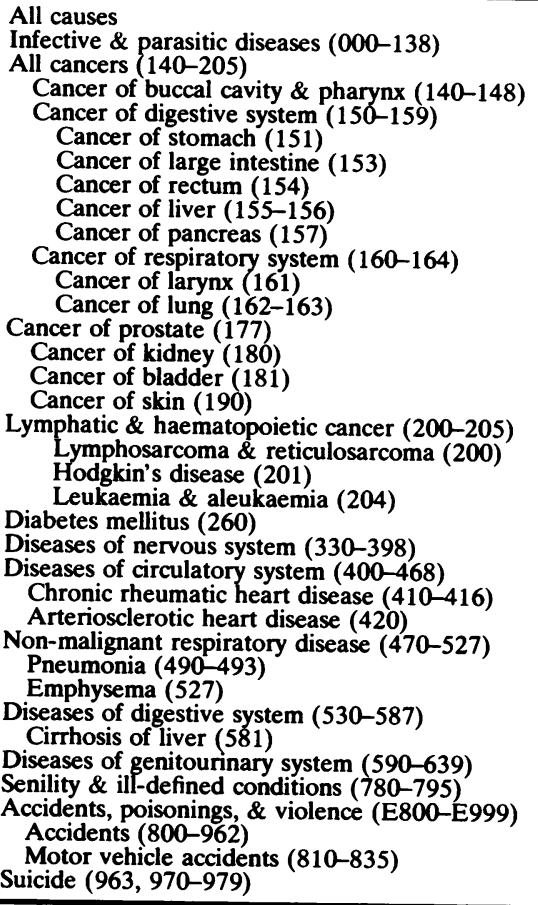 & $\begin{array}{c}65 \cdot 9 \dagger \\
9 \cdot 4 \dagger \\
82 \cdot 9 \dagger \\
63 \cdot 5 \\
84 \cdot 0 \\
53 \cdot 5 \\
103 \cdot 5 \\
46 \cdot 0 \\
145 \cdot 2 \\
86 \cdot 6 \\
85 \cdot 0 \\
58 \cdot 9 \\
86 \cdot 0 \\
98 \cdot 5 \\
95 \cdot 3 \\
117 \cdot 6 \\
49 \cdot 5 \\
69 \cdot 0 \\
85 \cdot 9 \\
79 \cdot 9 \\
88 \cdot 2 \\
34 \cdot 4 \dagger \\
49 \cdot 9 \dagger \\
60.0 \dagger \\
37 \cdot 9 * \\
56 \cdot 7 \dagger \\
63 \cdot 3 \dagger \\
46 \cdot 5 \dagger \\
118 \cdot 8 \\
58 \cdot 8 \dagger \\
71 \cdot 2 * \\
7 \cdot 3 \dagger \\
20.6 \dagger \\
93 \cdot 4 \\
97 \cdot 4 \\
87 \cdot 6 \\
91 \cdot 6 \\
\end{array}$ & $\begin{array}{c}100 \cdot 0 \\
15 \cdot 3^{*} \\
122 \cdot 5 \dagger \\
95 \cdot 9 \\
125 \cdot 7 \\
81 \cdot 9 \\
151 \cdot 1^{*} \\
70 \cdot 6 \\
230 \cdot 4^{*} \\
129 \cdot 4 \\
123 \cdot 5^{*} \\
87 \cdot 9 \\
124 \cdot 7^{*} \\
135 \cdot 9 \\
142 \cdot 1 \\
170 \cdot 4 \\
75 \cdot 4 \\
104 \cdot 7 \\
140 \cdot 6 \\
135 \cdot 4 \\
133 \cdot 5 \\
51 \cdot 8 \\
74 \cdot 7^{*} \\
91 \cdot 7^{*} \\
61 \cdot 5 \\
86 \cdot 2 \dagger \\
92 \cdot 7 \\
70 \cdot 9 \\
178 \cdot 7 \dagger \\
92 \cdot 0 \\
110.7 \\
11 \cdot 7 \dagger \\
30.5^{*} \\
146 \cdot 1 \dagger \\
156 \cdot 5 \dagger \\
143 \cdot 2^{*} \\
142 \cdot 5^{*}\end{array}$ & $\begin{array}{c}100 \cdot 0 \\
17 \cdot 2^{*} \\
124 \cdot 2 \dagger \\
107 \cdot 0 \\
125 \cdot 5 \\
78 \cdot 2 \\
149 \cdot 9^{*} \\
58 \cdot 9 \\
219 \cdot 9^{*} \\
134 \cdot 6 \\
121 \cdot 6 \\
97 \cdot 7 \\
122 \cdot 2 \\
139 \cdot 1 \\
159 \cdot 3 \\
168 \cdot 0 \\
85 \cdot 8 \\
106 \cdot 6 \\
157 \cdot 8 \\
102 \cdot 6 \\
135 \cdot 3 \\
31 \cdot 1^{*} \\
68 \cdot 4^{*} \\
92 \cdot 9 \\
69 \cdot 0 \\
88 \cdot 2 \dagger \\
95 \cdot 0 \\
72 \cdot 8 \\
176 \cdot 4 \dagger \\
84 \cdot 6 \\
101 \cdot 4 \\
13 \cdot 1^{*} \\
17 \cdot 2 \dagger \\
155 \cdot 3 \dagger \\
168 \cdot 7 \dagger \\
153 \cdot 0 \dagger \\
159 \cdot 1 \dagger\end{array}$ & $\begin{array}{r}100 \cdot 0 \\
79 \cdot 4 \\
102 \cdot 1 \\
66 \cdot 6 \\
122 \cdot 1 \\
57 \cdot 1 \\
186 \cdot 7 \\
105 \cdot 4 \\
101 \cdot 4 \\
72 \cdot 4 \\
102 \cdot 4 \\
103 \cdot 3 \\
117 \cdot 8 \\
134 \cdot 4 \\
63 \cdot 5 \\
86.0 \\
116.3 \\
112.1 \\
109.4\end{array}$ & $\begin{array}{r}100 \cdot 0 \\
87.0 \\
100.9 \\
62.9 \\
120 \cdot 1 \\
47 \cdot 2 \\
177 \cdot 3 \\
108 \cdot 5 \\
98 \cdot 5 \\
79 \cdot 4 \\
99 \cdot 0 \\
107 \cdot 9 \\
129.4 \\
133.2 \\
69.0 \\
85.1 \\
126.7 \\
79.8 \\
108.0\end{array}$ \\
\hline
\end{tabular}

*Statistically significant at 0.05 level.

†Statistically significant at 0.01 level.

greater among the active employees than in the total cohort. Results for the retirees were sometimes totally different. Thus if a study were done of union records of both active and retired, the proportion retired will be a potent determinant of the summary PMR. Although a PMR study based on union records would produce some spuriously high PMRs (compared with total cohort SMRs), it would produce no "false negatives." That is, there were no instances in these data where a significantly increased total cohort SMR would not have been reflected in a significant PMR increase. A raised PMR is not accurate enough to be considered definitive.

\section{Summary and conclusion}

Overall, there was incomplete agreement between the population based site specific cancer SMRs and the corresponding PMRs based on either all deaths or on union deaths only. For cancers, both total PMRs and union PMRs consistently overestimated the risk. In some cases-for example all cancers, stomach cancer, lung cancer, and bladder cancerthe overestimates were sufficient to turn deficits (significant or otherwise) into significant excesses. In addition, quite a few non-significant site specific cancer excesses were also falsely suggested by PMRs based on either set of deaths. As such, PMRs, regardless of whether they were based on complete or partial death ascertainment, were poor indicators for cancer risk, and produced a large number of false positives.

On the other hand, both total PCMRs and union PCMRs showed, in general, a resemblance to the corresponding site specific cancer SMRs, although the magnitude of individual PCMR was somewhat slightly higher. Both the total PCMRs and union PCMRs correctly showed the significant deficit and excess identified by the SMRs. Overall, PCMRs appeared to be better than PMRs for assessing the direction of site specific cancer risk, but they were still poor indexes for assessing the magnitude of risk. Such inaccuracies can be neither measured nor con- 
Table 11 Cause specific SMRs, total PMRs, union PMRs, total PCMRs, and union PCMRs for local 3-3A members who were most frequently dispatched in the high exposure category

\begin{tabular}{|c|c|c|c|c|c|}
\hline Cause of death (7th ICDA) & $S M R$ & $\begin{array}{l}\text { Total } \\
P M R\end{array}$ & $\begin{array}{l}\text { Union } \\
P M R\end{array}$ & $\begin{array}{l}\text { Total } \\
\text { PCMR }\end{array}$ & $\begin{array}{l}\text { Union } \\
\text { PCMR }\end{array}$ \\
\hline 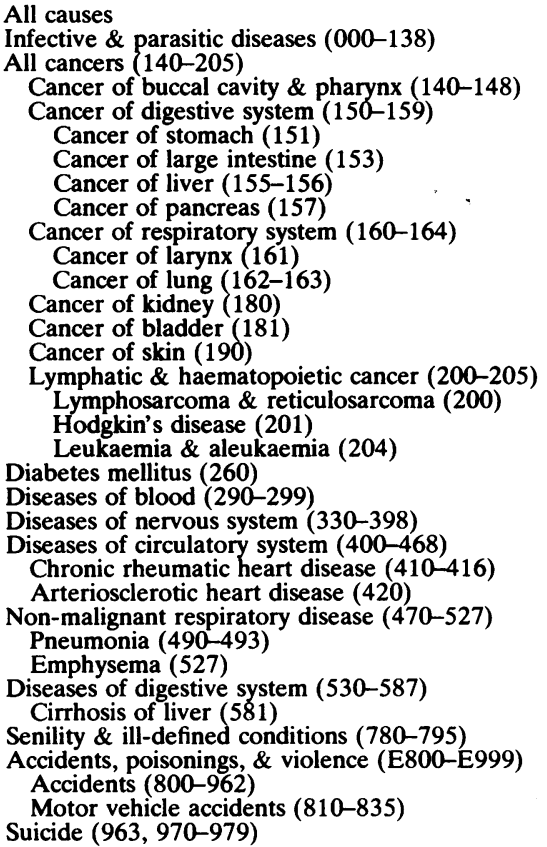 & $\begin{array}{c}70 \cdot 5 \dagger \\
17 \cdot 4^{*} \\
79 \cdot 8 \dagger \\
70 \cdot 9 \\
71 \cdot 5 \\
93 \cdot 5 \\
54 \cdot 9 \\
173 \cdot 4 \\
93 \cdot 4 \\
92 \cdot 3 \\
79 \cdot 1 \\
93 \cdot 8 \\
22 \cdot 7 \\
118 \cdot 5 \\
81 \cdot 3 \\
89.7 \\
130 \cdot 0 \\
123 \cdot 0 \\
16 \cdot 2^{*} \\
76.9 \\
137 \cdot 9 \\
57 \cdot 4 \dagger \\
61 \cdot 8 \dagger \\
82 \cdot 0 \\
58 \cdot 0 \dagger \\
75 \cdot 7 \\
93 \cdot 2 \\
87 \cdot 9 \\
72.9 \\
79 \cdot 5 \\
27 \cdot 3^{*} \\
95 \cdot 6 \\
113 \cdot 4 \\
95 \cdot 2 \\
65 \cdot 6\end{array}$ & $\begin{array}{c}100 \cdot 0 \\
26 \cdot 5 \\
110 \cdot 1 \\
99.7 \\
99 \cdot 6 \\
133 \cdot 3 \\
74 \cdot 6 \\
256 \cdot 5 \\
129 \cdot 9 \\
124 \cdot 9 \\
110 \cdot 1 \\
126 \cdot 6 \\
31 \cdot 4 \\
159 \cdot 3 \\
114 \cdot 7 \\
128 \cdot 1 \\
198 \cdot 4 \\
196 \cdot 4 \\
23 \cdot 1 \\
108 \cdot 5 \\
201 \cdot 1 \\
80 \cdot 0 \\
87 \cdot 7 * \\
124 \cdot 1 \\
82 \cdot 0 \dagger \\
103 \cdot 7 \\
132 \cdot 5 \\
65 \cdot 1 \\
104 \cdot 9 \\
113 \cdot 2 \\
38 \cdot 0 \\
142 \cdot 5 \dagger \\
173 \cdot 4 \dagger \\
148 \cdot 2^{*} \\
96 \cdot 5\end{array}$ & $\begin{array}{c}100 \cdot 0 \\
30 \cdot 7 \\
111 \cdot 9 \\
114 \cdot 8 \\
102 \cdot 3 \\
153 \cdot 2 \\
85 \cdot 8 \\
293 \cdot 8^{*} \\
112 \cdot 1 \\
128 \cdot 6 \\
126 \cdot 3 \\
129 \cdot 8 \\
36 \cdot 4 \\
181 \cdot 2 \\
90 \cdot 1 \\
118 \cdot 6 \\
183 \cdot 8 \\
152 \cdot 3 \\
26 \cdot 8 \\
93 \cdot 8 \\
231 \cdot 7 \\
87 \cdot 9 \\
90 \cdot 3 \\
120 \cdot 1 \\
85 \cdot 4^{*} \\
101 \cdot 5 \\
127 \cdot 1 \\
109 \cdot 1 \\
104 \cdot 8 \\
105 \cdot 6 \\
44 \cdot 2 \\
142 \cdot 1 \dagger \\
180 \cdot 7 \dagger \\
154 \cdot 9 * \\
80 \cdot 1\end{array}$ & $\begin{array}{r}100 \cdot 0 \\
89 \cdot 9 \\
90 \cdot 4 \\
121 \cdot 2 \\
67 \cdot 8 \\
234 \cdot 3 \\
118 \cdot 4 \\
112 \cdot 1 \\
98 \cdot 1 \\
113 \cdot 6 \\
28 \cdot 7 \\
139 \cdot 7 \\
116 \cdot 5 \\
119 \cdot 0 \\
185 \cdot 7 \\
194 \cdot 5 \\
21.4\end{array}$ & $\begin{array}{r}100.0 \\
101.9 \\
91.4 \\
137.1 \\
76.8 \\
264.2^{*} \\
100.6 \\
113.9 \\
110.9 \\
115.0 \\
32.7 \\
157.2 \\
89.7 \\
107.6 \\
167.4 \\
144.0 \\
24.1\end{array}$ \\
\hline
\end{tabular}

*Statistically significant at 0.05 level.

tStatistically significant at 0.01 level.

trolled.

For the entire cohort, both total PMRs and union PMRs appeared to be in close agreement with SMRs when non-malignant causes of death were considered, particularly for diseases of the circulatory system and the external causes of death (accidents and violence). Thus PMRs correctly identified all the significant excesses in non-malignant mortality, but produced some "false positives."

Analysis by duration of union membership and latency indicated that PMRs or PCMRs based on union deaths tended to overestimate the risk of lung cancer by a disproportionately larger amount in groups with shorter time than in groups with longer time. For PMRs (particularly union PMRs), even in the groups with a fairly long membership, the overestimate was severe enough to make them inappropriate for risk assessment. As such, contrary to what Waxweiler et al have suggested, ${ }^{13}$ PMRs, regardless of membership duration, are not acceptable as surrogates for SMRs. Furthermore, this differential bias by duration of membership had the net effect of reducing the gradient of any trend or eliminating the trend entirely. The same reasoning probably applies to other similar dose response anlyses, where the overestimation by PMRs or PCMRs operates differentially. As such, the study indicated that both $\exists$ PMR and PCMR are not sensitive in detecting trends in dose response analysis such as duration of membership or latency analysis. The differential bias of PMRs or PCMRs by latency or duration of membership (or duration of employment) has not 오 been reported previously. This finding may be useful $D$ in interpreting other studies, since the PMR or PCMR will be an average weighted by the latency $N$ and membership distribution. If other studies do not ${ }^{\circ}$ examine for the effect of latency and duration of 0 membership there is a danger that serious exaggera- $\mathbb{W}$ tion of risk may occur due to the weighting by으 latency and duration of membership within theo study population. Furthermore, in data such as these, the rise in SMR with increasing latency or $\stackrel{\oplus}{+}$ duration of membership (the slope) will be underes- 0 timated. Such distortions reinforce the need for extreme caution in interpreting PMRs and PCMRs.

The group of union members with no dispatch $\frac{\vec{Q}}{\mathbb{Q}}$ 
Table 12 Cause specific SMRs, total PMRs, total PCMRs, union PMRs, and union PCMRs for local 3-3A members who did not have any dispatch history

\begin{tabular}{|c|c|c|c|c|c|}
\hline Cause of death (7th ICDA) & $S M R$ & $\begin{array}{l}\text { Total } \\
\text { PMR }\end{array}$ & $\begin{array}{l}\text { Union } \\
\text { PMR }\end{array}$ & $\begin{array}{l}\text { Total } \\
\text { PCMR }\end{array}$ & $\begin{array}{l}\text { Union } \\
\text { PCMR }\end{array}$ \\
\hline All causes & $100 \cdot 1$ & $100 \cdot 0$ & $100 \cdot 0$ & & \\
\hline Infective \& parasitic diseases $(000-138)$ & 159.7 & $158 \cdot 5^{*}$ & $191 \cdot 7^{*}$ & & \\
\hline All cancers $(140-205)$ & $112 \cdot 0^{*}$ & $112.9 \dagger$ & $113 \cdot 7^{*}$ & $100 \cdot 0$ & $100 \cdot 0$ \\
\hline Cancer of buccal cavity \& pharynx $(140-148)$ & $100 \cdot 4$ & $100 \cdot 2$ & $125 \cdot 3$ & 88.8 & $108 \cdot 7$ \\
\hline Cancer of digestive system $(150-159)$ & 109.9 & 112.6 & $103 \cdot 3$ & $99 \cdot 6$ & $91 \cdot 4$ \\
\hline Cancer of stomach (151) & $199 \cdot 1 \dagger$ & $205.0 \dagger$ & $182.2^{*}$ & $180 \cdot 3 \dagger$ & $160 \cdot 5$ \\
\hline Cancer of large intestine (153) & $76 \cdot 4$ & 78.4 & $66 \cdot 1$ & $69 \cdot 3$ & 58.9 \\
\hline Cancer of rectum (154) & 79.8 & $82 \cdot 3$ & $85 \cdot 4$ & $72 \cdot 6$ & 75.5 \\
\hline Cancer of liver $(155-156)$ & 195.9 & $204 \cdot 0^{*}$ & $221 \cdot 2^{*}$ & $180 \cdot 6^{*}$ & $195 \cdot 1$ \\
\hline Cancer of pancreas (157) & $110 \cdot 2$ & 112.4 & $106 \cdot 4$ & 99.4 & 94.0 \\
\hline Cancer of respiratory system $(160-164)$ & $117 \cdot 2$ & $118 \cdot 2^{*}$ & $109 \cdot 1$ & $105 \cdot 3$ & $94 \cdot 0$ \\
\hline Cancer of larynx (161) & 94.4 & 95.7 & 96.6 & $85 \cdot 1$ & 85.0 \\
\hline Cancer of lung $(162-163)$ & $119 \cdot 3^{*}$ & $120 \cdot 3^{*}$ & 110.6 & $107 \cdot 2$ & $98 \cdot 0$ \\
\hline Cancer of prostate (177) & $105 \cdot 1$ & 113.8 & 119.2 & 100.8 & 111.6 \\
\hline Cancer of kidney (180) & 82.6 & 82.0 & $100 \cdot 3$ & $72 \cdot 4$ & 87.0 \\
\hline Cancer of bladder (181) & 119.0 & $126 \cdot 1$ & 129.5 & $111 \cdot 8$ & $118 \cdot 6$ \\
\hline Cancer of skin (190) & $182 \cdot 2$ & 168.9 & 191.0 & $145 \cdot 2$ & $151 \cdot 7$ \\
\hline Lymphatic \& haematopoietic cancer $(200-205)$ & 99.1 & $96 \cdot 3$ & 120.0 & 84.7 & 101.9 \\
\hline Lymphosarcoma \& reticulosarcoma $(200)$ & $101 \cdot 0$ & 97.9 & 155.5 & $85 \cdot 8$ & 129.4 \\
\hline Hodgkin's disease (201) & 61.9 & $54 \cdot 0$ & $58 \cdot 1$ & $47 \cdot 2$ & $44 \cdot 2$ \\
\hline Leukaemia \& aleukaemia (204) & $98 \cdot 3$ & $96 \cdot 6$ & $97 \cdot 3$ & $84 \cdot 6$ & $83 \cdot 0$ \\
\hline Benign neoplasms $(210-239)$ & $265 \cdot 9^{*}$ & $256 \cdot 1 \dagger$ & $328.3 \dagger$ & & \\
\hline Diabetes mellitus (260) & $90 \cdot 4$ & $91 \cdot 1$ & $94 \cdot 1$ & & \\
\hline Diseases of blood (290-299) & $125 \cdot 8$ & 126.8 & $163 \cdot 5$ & & \\
\hline Diseases of nervous system (330-398) & $76 \cdot 4^{*}$ & $79.0^{*}$ & 97.8 & & \\
\hline Diseases of circulatory system $(400-468)$ & $88 \cdot 4 \dagger$ & $90.0 \dagger$ & $92 \cdot 5^{*}$ & & \\
\hline Chronic rheumatic heart disease $(410-416)$ & $79 \cdot 2$ & $75 \cdot 7$ & 83.7 & & \\
\hline Arteriosclerotic heart disease $(420)$ & $82.9+$ & $84 \cdot 2+$ & $83.8 \dagger$ & & \\
\hline Non-malignant respiratory disease $(470-527)$ & $111 \cdot 7$ & $115 \cdot 7$ & $122 \cdot 8$ & & \\
\hline Pneumonia $(490-493)$ & $47.6+$ & $48.1 \dagger$ & $51 \cdot 9^{*}$ & & \\
\hline Emphysema (527) & $235 \cdot 5 \dagger$ & $251.7 \dagger$ & $272.6 \dagger$ & & \\
\hline Diseases of digestive system $(530-587)$ & 95.9 & $91 \cdot 4$ & 96.7 & & \\
\hline Cirrhosis of liver (581) & $100 \cdot 9$ & $93 \cdot 2$ & $87 \cdot 2$ & & \\
\hline Diseases of genitourinary system $(590-639)$ & $41 \cdot 7^{*}$ & $42 \cdot 2^{*}$ & $40 \cdot 3$ & & \\
\hline Senility \& ill-defined conditions $(780-795)$ & $26.5 \dagger$ & $25 \cdot 5+$ & $27 \cdot 0^{*}$ & & \\
\hline Accidents, poisonings, \& violence (E800-E999) & $135 \cdot 2 \dagger$ & 113.9 & $107 \cdot 2$ & & \\
\hline Accidents $(800-962)$ & $158 \cdot 1 \dagger$ & $133 \cdot 3 \dagger$ & $127 \cdot 3$ & & \\
\hline Motor vehicle accidents $(810-835)$ & $123 \cdot 2$ & $100 \cdot 0$ & 97.9 & & \\
\hline Suicide $(963,970-979)$ & $124 \cdot 6$ & $107 \cdot 0$ & $95 \cdot 7$ & & \\
\hline
\end{tabular}

${ }^{*}$ Statistically significant at 0.05 level.

†Statistically significant at 0.01 level.

history provided an interesting comparison of SMR, PMR, and PCMR. The overall SMR for this group was exactly 100 and, based on analytical considerations, PMRs should be close to SMRs. Indeed, in this subgroup the similarity between most cause specific SMRs and the corresponding total PMRs or

Table 13 Comparison of union PMRs in active and retired union members and SMRs for the entire cohort

\begin{tabular}{lllc}
\hline Category & \multicolumn{2}{l}{ Union PMR } & SMR \\
\cline { 2 - 3 } & Active & Retired & Total \\
\hline All cancers & $113^{*}$ & $127^{*}$ & $93^{*}$ \\
Stomach cancer & $182^{*}$ & 97 & $117^{*}$ \\
Liver cancer & $294 \dagger$ & $217^{*}$ & $167^{*}$ \\
Lung cancer & 110 & $129 \dagger^{\dagger}$ & 99 \\
Bladder cancer & $30 \dagger^{\dagger}$ & 94 & 118 \\
Emphysema & $161^{*}$ & $24 \dagger^{\dagger}$ & $165^{\dagger}$ \\
Accidents & $193 \dagger$ & 71 & $127^{\dagger}$ \\
Suicide & 118 & 132 & 97 \\
\hline
\end{tabular}

${ }^{*}$ Statistically significant at 0.05 level.

† Statistically significant at 0.01 level. union PMRs was remarkable, including site specific cancers. This observation was in direct contradiction to the finding in the entire cohort, where PMRs consistently overestimate the risk. On the other hand, PCMRs based on total deaths or union deaths in the group without dispatch history consistently underestimate the site specific cancer risk, contrary to the situation of a high degree of agreement between SMR and PCMR for the entire cohort. In fact, union PCMRs failed to predict the significant excesses in stomach cancer and in cancer of the lung in this subcohort.

Whether PMR or PCMR is the more appropriate index for cancer risk assessment depends on, to a large extent, whether the underlying overall SMR or the underlying all cancer SMR is close to 100 . For a large cohort, one might rely on previous experience and assume that the healthy worker effect most likely operates in the entire cohort. But when one is dealing with smaller groups, the assumption of a modest healthy worker effect $(\mathrm{SMR}=80)$ is no 
longer safe, and the usefulness of either PMR or PCMR is no longer clear.

In conclusion, we find that for this union the PMR/PCMR approach would miss few important rises in risk, but would likely produce "false positives." In general, the PCMR appears less inaccurate than the PMR but not consistently so, especially in small subcohorts. Both PMR and PCMR were biased by latency or duration of union membership, an important thought when considering other studies. The main usefulness of the PMR/PCMR approach is limited to hypothesis generation. They are not particularly useful or reliable measures of the magnitude of risk, and should not be used to draw conclusions. Finally, it should be emphasised again that vital status ascertainment based on records of this particular union was exceptionally complete $(74 \%)$, because of its membership and benefits policy. Therefore, a high degree of agreement between SMR and PMR/PCMR in this study was originally expected. Unfortunately, such a high agreement was not found in our analysis. As such, PMRs or PCMRs based on less complete data from other unions may be expected to be even more inaccurate.

We thank the American Industrial Health Council and the American Petroleum Institute, sponsors of the study, and the staff of the International Union of Operating Engineers, Local No 3, and their trust fund administrators, C W Sweeney \& Co, for their continued participation and guidance.

\section{References}

' Thomas TL, Decoufle P, Moure-Eraso R. Mortality among workers employed in petroleum refining and petrochemical plants. J Occup Med 1980;22:97-103.

${ }^{2}$ Thomas TL, Waxweiler RJ, Moure-Eraso R, Itaya S, Fraumen JF. Mortality patterns among workers in three Texas oil refineries. J Occup Med 1982;24:135-41.

${ }^{3}$ Thomas TL, Decoufle P. Mortality among workers employed in the pharmaceutical industry. J Occup Med 1979;21:619-23.

${ }^{4}$ Thomas T. A preliminary investigation of mortality among workers in the pottery industry. Int $J$ Epidemiol 1982;11:175-80.
${ }^{5}$ Dalager NA, Mason TJ, Fraumeni JF, Hoover R, Payne WW. Cancer mortality among workers exposed to zinc chromate paints. J Occup Med 1980;22:25-9.

- Blair A. Mortality among workers in the metal polishing and $\overrightarrow{\vec{F}}$ plating industry, 1951-1969. J Occup Med 1980;22:158-62.

${ }^{7}$ Kaminski R, Geissert KS, Dacey E. Mortality analysis of plumbers and pipefitters. J Occup Med 1980;22:183-9.

${ }^{8}$ Wong $\mathrm{O}$. An epidemiologic mortality study of a cohort of chemi- $\overline{\bar{\omega}}$ cal workers potentially exposed to formaldehyde, with a dis- $\vec{D}$ cussion on SMR and PMR. In: Gibson JE, ed. Formaldehyde $\varrho$ toxicology. Washington: Hemisphere Pub Corp, 1983.

Wong $\mathrm{O}$, Tabershaw IR. Comments on mortality among workers $\mathrm{C}$ employed in petroleum refining and petrochemical plants. $J \overrightarrow{0}$ Occup Med 1980;22:638-40.

${ }^{10}$ Wong O, Decoufle P. Methodological issues involving SMR and $\overrightarrow{\vec{\omega}}$ PMR in occupational studies.J Occup Med 1982;24:299-304. O

" Redmond CK, Breslin PP. Comparison of methods for assessing occupational hazards. J Occup Med 1975;17:313-7.

12 Kupper LL, McMichael AJ, Symons MJ, Most BM. On the utility of proportional mortality analysis. J Chronic Dis $\vec{N}$ 1978;31:15-22.

${ }^{13}$ Waxweiler RJ, Haring MK, Lettingwell SS, Halperin WH, Quantification of differences between proportionate mortality $\frac{\overrightarrow{0}}{c}$ ratios and standardized mortality ratios. (Banbury report 9.) Quantifications of Occupational Cancer 1981;379-89.

14 Beaumont JJ, Leet TL, Okun AH. Occupational data sets appropriate for proportionate mortality ratio analysis. (Ban-

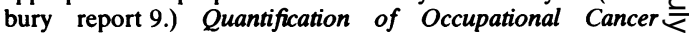
$1981 ; 391-411$.

is Wen CP, Tsai SP, Weiss NS, McClellan W, Gibson RL. A $\vec{\varphi}$ population-based cohort study of brain tumor mortality among $\circlearrowleft$ oil refinery workers with a discussion of methodological issues of SMR and PMR. (Banbury Report 9.) Quantification of Occupational Cancer 1981;413-32.

${ }^{16}$ Decoufle P, Thomas TL, Pickle LW. Comparison of the proportionate mortality ratio and standardized mortality ratio risk measures. Am J Epidemiol 1980;111:263-9.

17 John LR, Marsh GM, Enterline PE. Evaluating occupational $\varrho$ hazards using information known only to employees: a comparative study. Br J Ind Med 1983;40:346-52.

18 Wong O, Morgan RW, Kheifets L, Larson SR, Whorton MD. Mortality among members of a heavy construction equipment operators union with potential exposure to diesel exhaust emissions. $\mathrm{Br} \mathrm{J}$ Ind $\mathrm{Med}$ 1985;42:435-48.

14 World Health Organisation. International classification of diseases. 7th rev. Geneva: WHO, 1982.

${ }^{20}$ Marsh GM, Preninger M. OCMAP, a user-oriented occupational cohort morality analysis program. American Statistician $1980 ; 34: 245$

${ }^{21}$ Fox AJ, Collier PF. Low mortality rates in industrial cohort studies due to selection for work and survival in the industry. Br J Prev Soc Med 1976;30:225-30.

${ }^{22}$ McMichael AJ. Standardized mortality ratios and the "healthy worker effect"; scratching beneath the surface. J Occup Med $\frac{T}{O}$ 1976; 18: 155-68. 